\title{
Advances in Environmental Studies
}

\section{The Role of Chitosan (CHS) and Chitosan-Silver Nanoadsorbents (COMP) in Adsorption of $\mathrm{Cu}$ (II) and Fe (II) lons from Electroplating Wastewater}

\author{
A Sumaila ${ }^{1,2 *}$, MM Ndamitso $^{1}$, YA lyaka $^{1}$, AS Abdulkareem $^{3}$ and JO Tijani ${ }^{1}$ \\ ${ }^{1}$ Department of Chemistry, Federal University of Technology Minna, Niger State, Nigeria \\ ${ }^{2}$ Department of Pure and Industrial Chemistry, Kogi State University Anyigba, Kogi State, Nigeria \\ ${ }^{3}$ Department of Chemical Engineering, Federal University of Technology Minna, Niger State, Nigeria
}

\begin{abstract}
In this work, green development of CHS-silver nanocomposite (COMP) using aqueous leaf extracts of Nicotiana tabacum and silver nitrate as reducing agent and precursor respectively. The prepared CHS and COMP were characterized by ultraviolet-visible (UV-Vis) spectroscopy, X-ray diffraction (XRD) and Fourier Transform Infrared (FTIR) Spectroscopy. The CHS and nanocomposite were employed to remove copper and iron metal ions from electroplating wastewater via batch adsorptions process. The XRD results of the nanocomposite confirmed the formation of COMP. The BET results showed increased in surface area of CHS from 12.67 to $139.20 \mathrm{~m}^{2} / \mathrm{g}$ after doped with nanosilver. The maximum percentage removal of copper and iron by COMP were $94.76 \%$ and $98.80 \%$ respectively under the applied conditions of $348 \mathrm{~K}$ (temperature), 60 minutes (contact time) using $25 \mathrm{mg}$ (adsorbent dosage). The isotherm data were well best fitted to Jovanovic isotherm model. While kinetic data followed the pseudo-second order model, an indication of chemical adsorption. This study showed that COMP with high adsorption efficiency can be used successfully to adsorbed copper and iron from electroplating wastewater.
\end{abstract}

Keywords

Nicotiana tabacum, Electroplating wastewater, Adsorption, Crab shell, Nanocomposite

\section{Introduction}

The contamination of environment by potentially toxic metals is one of the foremost hazards threatening human and aquatic species, thus the need for urgent attention on how to curb it [1]. These toxic metals find their way into the environment through release of geogenic, industrial, agricultural, pharmaceutical, and domestic wastewater. Through food chain, the heavy metals enter and accumulate in living tissues and become detrimental to human health $[2,3]$. Exposure to dose of heavy metals can result to damage or failure of essential human organs such as liver; kidney, cancer and brain [3]. In view of this, heavy metal ions must be removed prior to discharge into water bodies.

Electroplating wastewater as an industrial wastewater is a large volume of wastewater discharge from electroplating process. This industrial wastewater can be acidic or alkaline, depends on the nature of production however contain heavy metals usually at elevated levels according to the kind of metal solution used in the process [4]. Among the heavy metals usually present in electroplating wastewater are copper and iron. The presence of high amount of these metals has been reported to cause health disorderliness range from stomach ache to liver to damage [3]. Hence, their release to the environment is disastrous to human life, it is therefore important that electroplating wastewater be adequately treated using suitable treatment technique before discharge into the environment.

Over the years, there have been series techniques employed to remove heavy metals from electroplating wastewater [5]. Prominent among these techniques are co-precipitation, precipitation, reverse osmosis, chemical coagula-

*Corresponding author: A Sumaila, Department of Chemistry, Federal University of Technology Minna, Niger State; Department of Pure and Industrial Chemistry, Kogi State University Anyigba, Kogi State, Nigeria

Accepted: November 05, 2020

Published online: November 07, 2020

Citation: Sumaila A, Ndamitso MM, lyaka YA, et al. (2020) The Role of Chitosan (CHS) and Chitosan-Silver Nanoadsorbents (COMP) in Adsorption of $\mathrm{Cu}$ (II) and Fe (II) lons from Electroplating Wastewater. Adv Environ Stud 4(2):318-330 
Citation: Sumaila A, Ndamitso MM, lyaka YA, et al. (2020) The Role of Chitosan (CHS) and Chitosan-Silver Nanoadsorbents (COMP) in Adsorption of $\mathrm{Cu}$ (II) and Fe (II) lons from Electroplating Wastewater. Adv Environ Stud 4(2):318-330

tion, electrodialysis, flocculation, membrane separation and ion-exchange [6]. Nevertheless, these methods often involve certain major limitations such as high energy needs, inefficient metal removal, and production of a large amount of toxic waste, cost of operation, complex reaction and uses of heavy chemicals [7]. The process of adsorption using biomaterials to remove heavy metals from industrial wastewater is considered to be a simple and effective technique in wastewater management [8]. Numerous studies have shown the potential to use these materials to remove heavy metal ions from industrial wastewater due to their effectiveness, low cost, biodegradability and large-scale use [9].

Biomaterials, particularly those of shellfishes are generated in large quantities as waste [10]. These wastes are biodegradable, their careless disposals in large quantities result to accumulation of wastes in public waters and landfills, and if left for a while, they decomposed causing odours which impair soil and water quality [11]. Thus, they can be converted into useful adsorbent like CHS.

Meanwhile, sequestrations of heavy metals from environment particularly water bodies using CHS have been studied by numerous researchers [9]. The removal of $\mathrm{Cu}$ (II) ion onto locally prepared and industrial CHS was investigated by [7]. Also, the potential of CHS for the adsorption of selected metal ions $\left(\mathrm{Pb}^{2+}, \mathrm{Fe}^{2+}\right.$ and $\left.\mathrm{Cu}^{2+}\right)$ from aqueous solutions was studied by Sobhanardakani, et al., [12]. Despite the fact that there are existing works relating to the use of CHS prepared from sea shells as adsorbents for removal of toxic metals from wastewater, the green preparation of CHS-silver nanocomposites and it use as adsorbent has not been extensively addressed. This article therefore examines this aspect of the production of CHS-silver nanocomposites and then studies its absorption behaviour to adsorb $\mathrm{Fe}^{2+}$ and $\mathrm{Cu}^{2+}$ ions from electroplating wastewater through batch-wise experimental processes.

\section{Materials and Methods}

\section{Materials}

Nicotiana tabacum leaves were obtained from a vegetable plantation in Paiko Tunga Awuje in the state of Niger, Nigeria. Crab shells were obtained from fish market in New Bussau Nigeria. All the chemicals used in this study were of analytical grade. The wastewater was obtained from electroplating plant in Nigeria.

\section{Method}

Extraction of CHS from Crab Shells: The production of CHS from the powdered crab shells was carried out via three main stages of extraction: Deproteinization, demineralization and deacetylation. The crab shells were deproteinized by treating 5 grams of the crab shells in $250 \mathrm{~cm}^{3}$ beaker using $1.25 \mathrm{M} \mathrm{NaOH}$ for $3 \mathrm{hrs}$ at room temperature. After which the mixtures was allow to settle; excess $\mathrm{NaOH}$ was filtered off and then washed with deionized water until neutral $\mathrm{pH}$. Filtration was done using Whatmann filter paper No 4, the residue were oven dried at temperature of $80^{\circ} \mathrm{C}$ for 45 minutes to obtain deproteinized crab shells.

In the case of demineralization of the deproteinized crab shells, 3 grams of the deproteinized crab shells was treated in $250 \mathrm{~cm}^{3}$ conical flask using $1.25 \mathrm{M}$ of $\mathrm{HCl}$ for $5 \mathrm{hrs}$ at temperature of $80{ }^{\circ} \mathrm{C}$. After heating, the mixtures was allow to cooled and settled; excess $\mathrm{HCl}$ was removed by decantation, then washed with deionized water until neutral $\mathrm{pH}$. This was subsequently filtered using Whatmann filter paper No 4 and the residues obtained were oven dried at $80^{\circ} \mathrm{C}$ for 45 minutes to obtain chitin.

To carry out the deacetylation of the obtained chitin to produce $\mathrm{CHS}, 1$ gram of the chitin in $100 \mathrm{~cm}^{3}$ beakers was treated using $0.5 \mathrm{M}$ of $\mathrm{NaOH}$ for $2 \mathrm{hrs}$ at temperature of 100 ${ }^{\circ} \mathrm{C}$. After heating, the mixture was allow to cooled and settled; The excess $\mathrm{NaOH}$ was removed by decantation, then rinsed with deionized water until neutral $\mathrm{pH}$. After then, it was filtered using Whatman filter paper No. 4, the residue was dried in an oven at $80^{\circ} \mathrm{C}$ for 45 minutes to obtain $\mathrm{CHS}$.

Preparation of aqueous leaf extract of Nicotiana tabacum: Fresh leaves of Nicotiana tabacum were washed with distilled water, dried in the sun and then finely ground. $10 \mathrm{~g}$ of ground leaf was added to $100 \mathrm{~cm}^{3}$ of distilled water, boiled in a water bath at $80^{\circ} \mathrm{C}$ for 15 minutes, then cooled and filtered through Whatman No. 1 filter paper, then stored at room temperature for further use. The phytochemical analysis was conducted on the extract to determine the presence of phenolic compounds.

Development of COMP: COMP was developed by mixing $40 \mathrm{~cm}^{3}$ of $1 \mathrm{M} \mathrm{AgNO}_{3}$ and $40 \mathrm{~cm}^{3}$ of $1.0 \mathrm{wt} \% \mathrm{CHS}$ solutions in a $100 \mathrm{~cm}^{3}$ conical flasks. This followed by addition of $5 \mathrm{~cm}^{3}$ aqueous leaf extract of Nicotiana tabacum and stirred on a magnetic stirrer at $250 \mathrm{rpm}$ for $2 \mathrm{~h}$ and then allowed to age for $24 \mathrm{~h}$. The reduction of silver nitrate to nanosilver was observed using an Ultraviolet-visible spectrophotometer-1800 series. The obtained COMP was lyophilized at $42{ }^{\circ} \mathrm{C}$, which was then stored for further characterization.

Characterization of the CHS and COMP: The formation of nanosilver in the COMP was determined an Ultraviolet-visible spectrophotometer-1800 series. The phase structure, surface morphologies, functional groups present and surface area/ pore of the prepared CHS and COMP were examined using XRD-6000 Shimadzu Scientific Instruments, Zeiss Auriga High Resolution Scanning Electron Microscope (HRSEM), Frontier FT-IR Perkin Elmer, UK and Brunauer Emmett Teller (BET) respectively.

Batch adsorption studies: The concentrations of $\mathrm{Cu}$ and Fe ions in the wastewater before and after adsorption were determined using Atomic absorption spectrophotometer (AAS) (Bulk Scientific AAS: Model Accusys 211 USA. Adsorption activities of the adsorbents (CHS and COMP) were evaluated at different contact time, adsorbent dosage and temperature using $50 \mathrm{~cm}^{3}$ of the electroplating wastewater and stirring speed of $200 \mathrm{rpm}$. After adsorption, the mixtures were filtered with Whatmann filter paper No 4 and the amounts of the heavy metals remaining in the wastewater were determined using AAS.

Determination of influence of contact time on the adsorption process: The influence of contact time on the ad- 


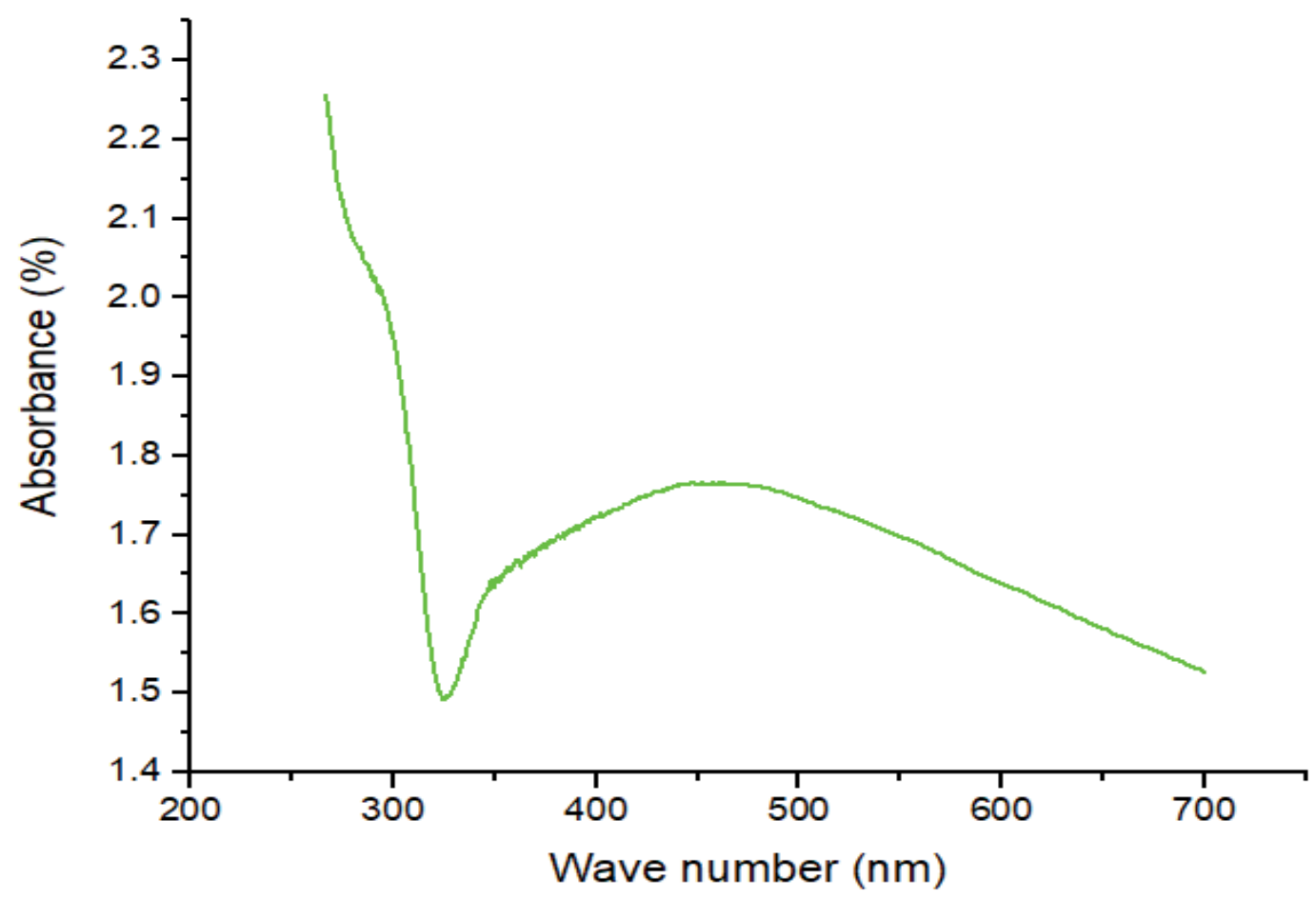

Figure 1: UV-visible spectrum of COMP.

sorption of $\mathrm{Cu}$ and Fe from the electroplating wastewater was investigated by contacting $25 \mathrm{mg}$ of adsorbent dosage of the adsorbents with $50 \mathrm{~cm}^{3}$ of the wastewater agitated at speed of $200 \mathrm{rpm}$ for $15,30,45,60,75$ minutes at room temperature. The adsorbents were separated from the mixtures by centrifugation and the supernatants were analyzed for the residual concentrations of heavy metal ions using AAS.

Determination of influence of adsorbent dose on the adsorption process: The adsorptions of $\mathrm{Cu}$ and Fe by CHS and COMP were studied at room temperature using different adsorbent dosages of $5,10,15,20$ and $25 \mathrm{mg}$ and $50 \mathrm{~cm}^{3}$ of electroplating wastewater for optimum contact time at stirring speed of $200 \mathrm{rpm}$. The adsorbents were removed from the solution by centrifugation and the supernatants were analyzed for the residual concentrations of $\mathrm{Cu}$ and Fe ions using AAS.

Determination of influence of temperature on the adsorption process: The optimum adsorbent dosage obtained was taken to monitor the effect of temperature on adsorption process. The adsorption experiments were carried out at different temperature of $303,318,333,348$ and $363 \mathrm{~K}$ with an optimum adsorbent dosage established and agitated at speed of $200 \mathrm{rpm}$. The adsorbents were separated from the mixtures by centrifugation and the supernatants were analyzed for the residual concentrations of $\mathrm{Cu}$ and Fe ions using AAS.

Data analysis: The equation 1 was employed to determine the amount of $\mathrm{Cu}$ and $\mathrm{Fe}$ ions removed.

$$
\mathrm{q}_{\mathrm{e}}=\frac{\left(\mathrm{C}_{\mathrm{o}}-\mathrm{C}_{\mathrm{e}}\right) \mathrm{V}}{\mathrm{m}}
$$

Implies that $\mathrm{C}_{\mathrm{o}}$ and $\mathrm{C}_{\mathrm{e}}$ are amounts $(\mathrm{mg} / \mathrm{l})$ of the selected metal ions before and after removal, respectively, $\mathrm{V}$ is the volume of wastewater in $\mathrm{cm}^{3}$ and $\mathrm{m}$ is the dose of the adsorbents in grams.

$$
\operatorname{Removal}(\%)=\frac{\mathrm{C}_{\mathrm{o}}-\mathrm{C}_{\mathrm{e}}}{\mathrm{C}_{\mathrm{o}}} \times 100
$$

The equation 2 was employed to determine the percentage removal of the selected metal ions. Where $C_{0}$ is the initial concentration of heavy metals $\left(\mathrm{mg} / \mathrm{dm}^{3}\right), C_{e}$ is the equilibrium concentration of the heavy metals $\left(\mathrm{mg} / \mathrm{dm}^{3}\right)$, and $R$ is the adsorption percentage. All the model parameters were evaluated by linear regression using Microsoft Excel. Apart from the correlation coefficient $\left(R^{2}\right)$, standard error (S.E) was also used to measure the goodness-of-fit. The smaller S.E. value indicates the better curve fitting.

\section{Results and Discussions}

\section{UV-visible spectroscopy analysis of CHS and COMP}

The formation of nanosilver by reduction of $\mathrm{Ag}^{+}$ions was observed by UV-visible spectroscopy. During the reduction process, the colourless $\mathrm{CHS}$ solution containing $\mathrm{AgNO}_{3}$ gradually turned brown, signifying the transformation of $\mathrm{Ag}^{+}$into $\mathrm{Ag}^{0}$ [13]. The presence of nanosilver in the composite material was confirmed by the UV-visible spectrum (Figure 1) with a maximum absorption band at $447 \mathrm{~nm}$, which is in the range of the typical plasmon resonance band of nanosilver [13] as shown on the UV-visible spectrum of COMP in Figure 1.

\section{FTIR of CHS and COMP}

The FTIR spectrum of the CHS (Figure 2a) showed peaks 


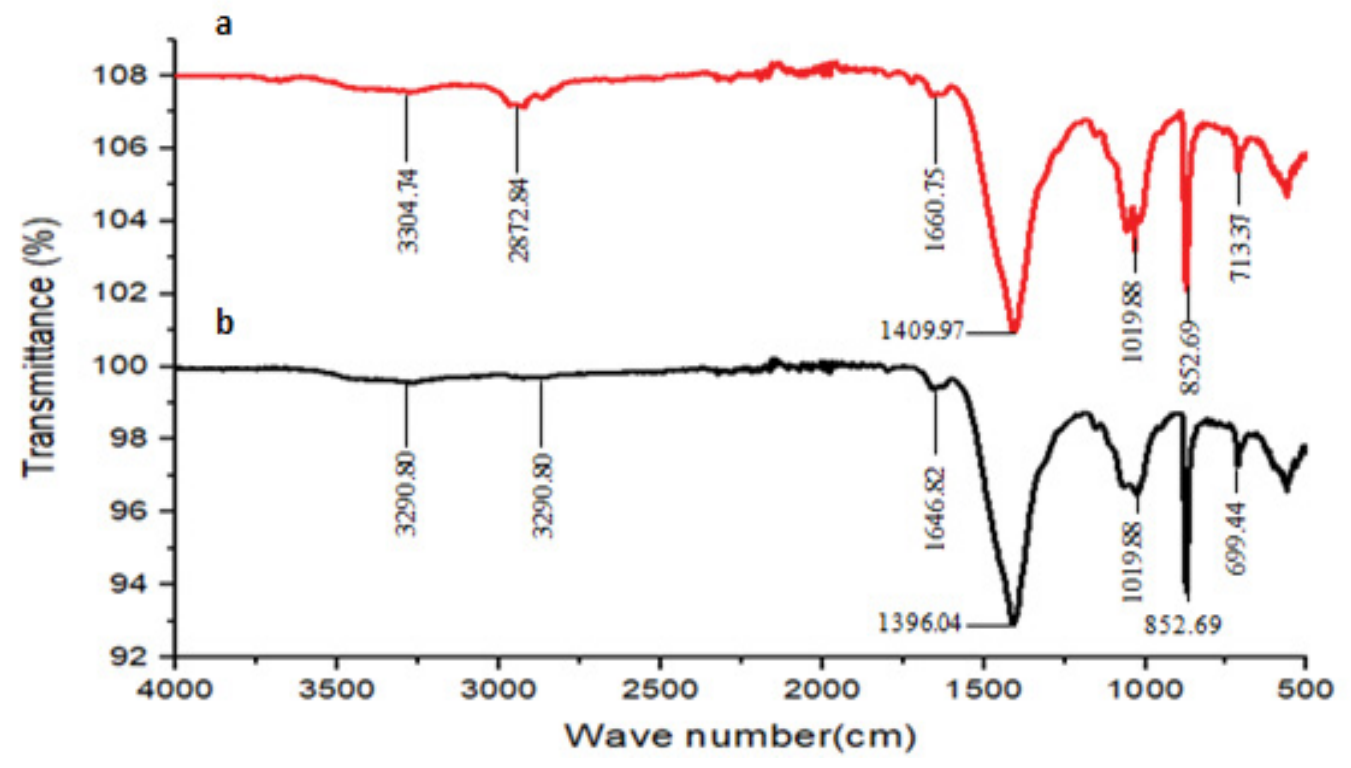

Figure 2: FTIR of (a) CHS; (b) COMP.

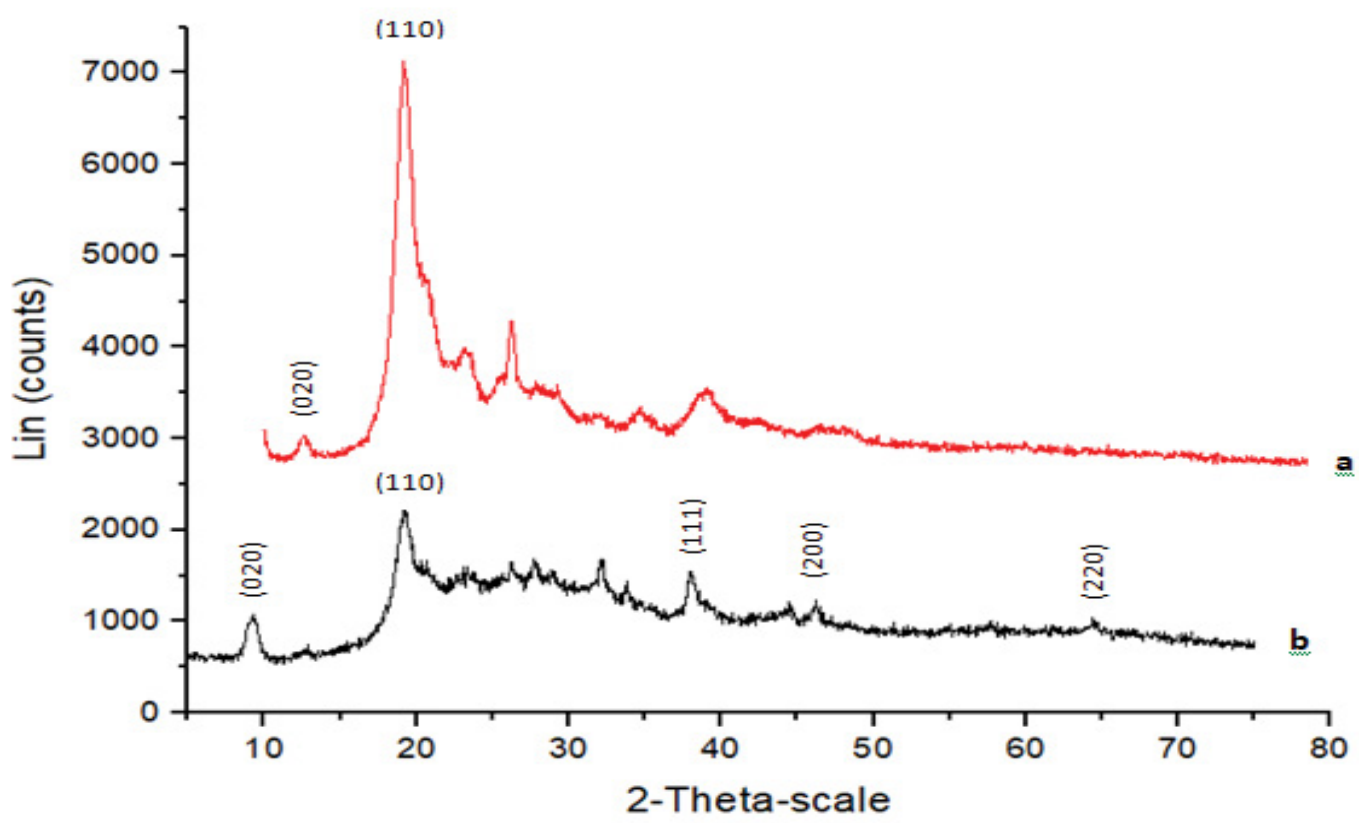

Figure 3: Diffractogram of (a) CHS; (b) COMP.

at $3304.74,2872.84,1660.75,1409.97,1033.81,866.62$ and $713.37 \mathrm{~cm}^{-1}$ The absorption peak at $3304.74 \mathrm{~cm}^{-1}$ is attributed to the overlapped peaks of the $\mathrm{N}-\mathrm{H}$ and $\mathrm{O}-\mathrm{H}$ stretching vibration [14]. The absorbance peaks at $2872.84 \mathrm{~cm}^{-1}, 1660.75 \mathrm{~cm}^{-1}$ and $1409.97 \mathrm{~cm}^{-1}$ indicate the $\mathrm{C}-\mathrm{H}$ stretching of polymeric link, $\mathrm{N}-\mathrm{H}$ in-plane bend and $\mathrm{O}-\mathrm{H}$ deformation in-plane respectively [15]. The characteristic absorption peaks at 1033.81 and $866.62 \mathrm{~cm}^{-1}$ are attributed to $\mathrm{C}-\mathrm{O}$ stretching of $\mathrm{O}-\mathrm{H}$ groups due to deformation [16-18]. The peak observed at 713.37 $\mathrm{cm}^{-1}$ is attributed to $\mathrm{N}-\mathrm{H}$ [17].

From the FTIR spectrum (Figure $2 b$ ) of the COMP, it is observed that the nanocomposites show similar surface func- tional groups which are alike to that shown by CHS. However, all the nanocomposites have it absorption intensities varied and frequencies of $\mathrm{O}-\mathrm{H}$ deformation in-plane and $\mathrm{N}-\mathrm{H}$ inplane bending shifted. This trend displayed by the nanocomposites shows a successful coordination of $-\mathrm{OH}$ and $-\mathrm{NH}_{2}$ of CHS with the silver metal center and indicates that the silver nanoparticles were successfully linked onto the CHS polymer matrix via similar coordination manners of the silver nanoparticle [19]. Though, the shifting in frequencies to lower or higher wave numbers as well as the change in the absorption intensities are attributed to the ratio of silver ion to $\mathrm{CHS}$ in the nanocomposites [20]. 
Citation: Sumaila A, Ndamitso MM, lyaka YA, et al. (2020) The Role of Chitosan (CHS) and Chitosan-Silver Nanoadsorbents (COMP) in Adsorption of $\mathrm{CU}$ (II) and Fe (II) lons from Electroplating Wastewater. Adv Environ Stud 4(2):318-330

\section{XRD Results of CHS and COMP}

XRD technique was employed to investigate the phase formations of the both CHS and COMP and the diffractogram are displayed as Figure $3 a$ and Figure $3 \mathrm{~b}$ respectively. The significant peaks at $2 \theta$ of $12.56^{\circ}$ and $19.20^{\circ}$ showed in Figure $3 a$ which correspond with crystal planes (020) and (110) are usually of semi-crystalline CHS. Also, the diffraction peaks at $9.29^{\circ}$ and $19.30^{\circ}$ with crystal planes (020) and (110) in Figure $3 \mathrm{~b}$ matched well with XRD pattern of CHS. In the same vein, Figure $3 \mathrm{~b}$ shows weak but sharp diffraction peaks at $2 \theta$ of $38.04^{\circ}, 44.65^{\circ}$ and $64.45^{\circ}$ assigned (111), (200) and
(220). These diffraction peaks matched well with that of silver nanoparticles [21]. While other peaks may be originated from the molecules of leaf extract [22].

\section{BET of CHS and COMP}

Determination of specific surface areas, pore sizes and pore volumes of the CHS and COMP were carried out by nitrogen gas adsorption-desorption at $77 \mathrm{~K}$. Specific total surface areas were determined using the Brunauer Emmett Teller (BET) (Figure 4 and Figure 5).

Table 1 shows that the surface area, pore volume and
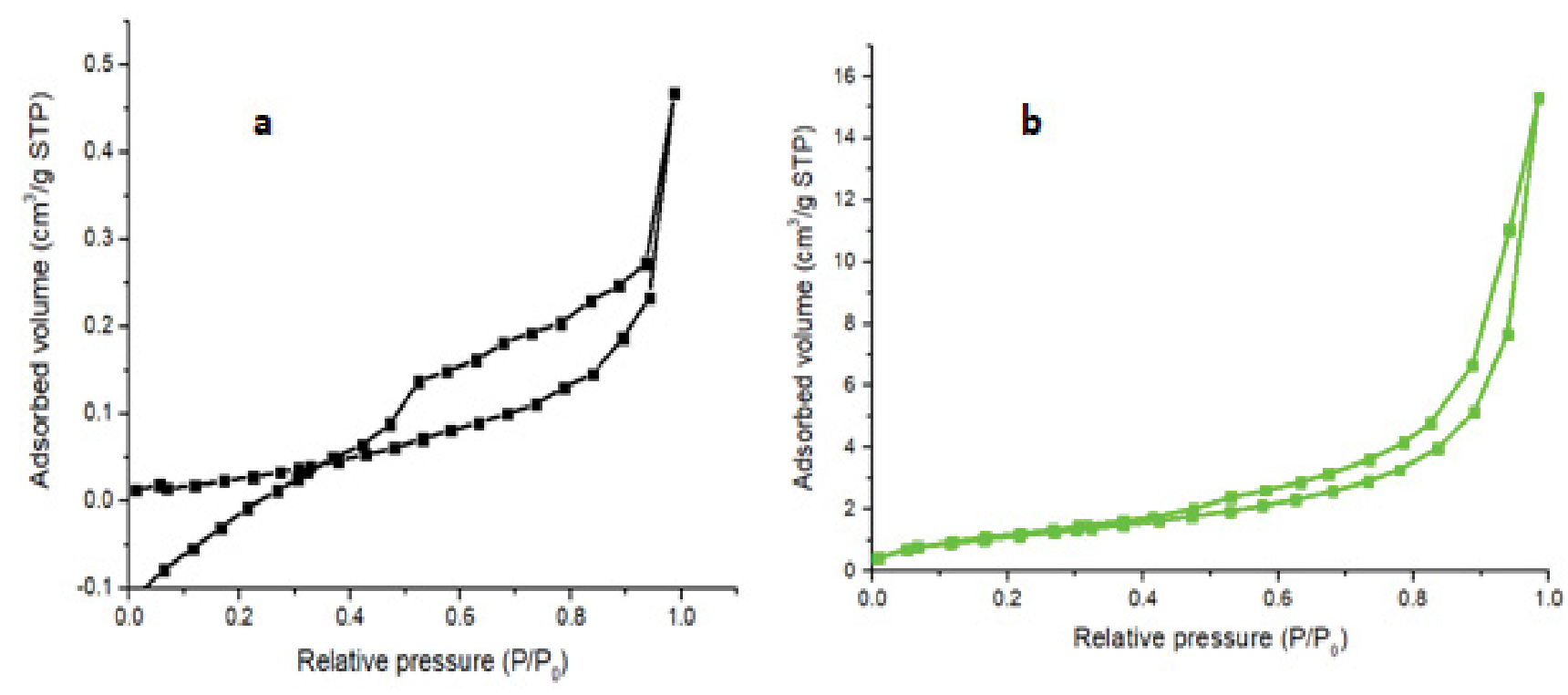

Figure 4: Adsorption isotherm of (a) CHS; (b) COMP using nitrogen at $77 \mathrm{~K}$.

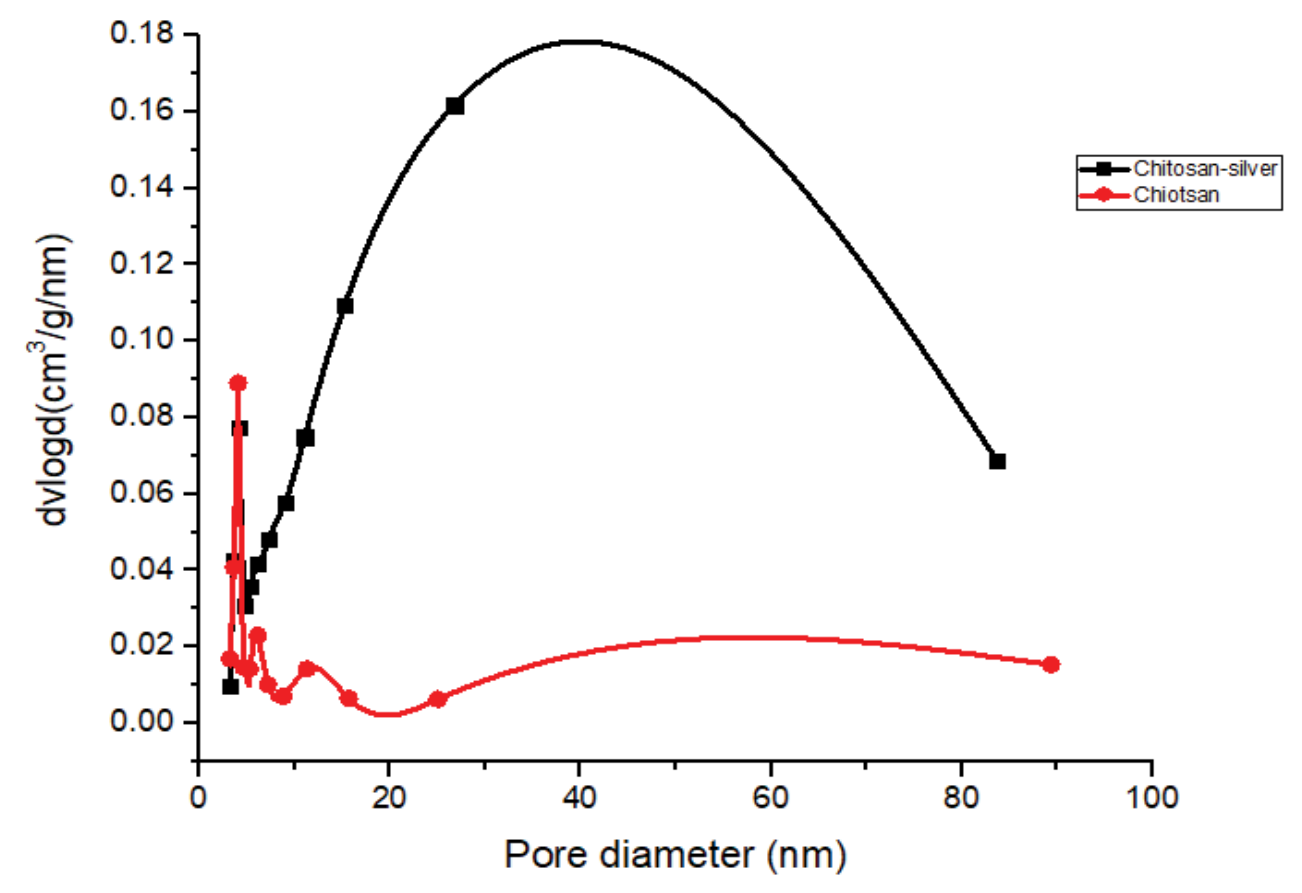

Figure 5: Pore size distributions for CHS and COMP. 
Citation: Sumaila A, Ndamitso MM, lyaka YA, et al. (2020) The Role of Chitosan (CHS) and Chitosan-Silver Nanoadsorbents (COMP) in Adsorption of $\mathrm{Cu}$ (II) and Fe (II) lons from Electroplating Wastewater. Adv Environ Stud 4(2):318-330

Table 1: Results of BET analysis of CHS and COMP.

\begin{tabular}{|c|c|c|c|c|}
\hline $\mathrm{S} / \mathrm{N}$ & Material & Surface area $\left(\mathrm{m}^{2} / \mathrm{g}\right)$ & Pore volume $\left(\mathrm{cm}^{3} / \mathrm{g}\right)$ & Pore size $(\mathrm{nm})$ \\
\hline 1 & $\mathrm{CHS}$ & 12.67 & 0.0266 & 4.035 \\
\hline 2 & COMP & 33.46 & 0.1347 & 4.078 \\
\hline
\end{tabular}
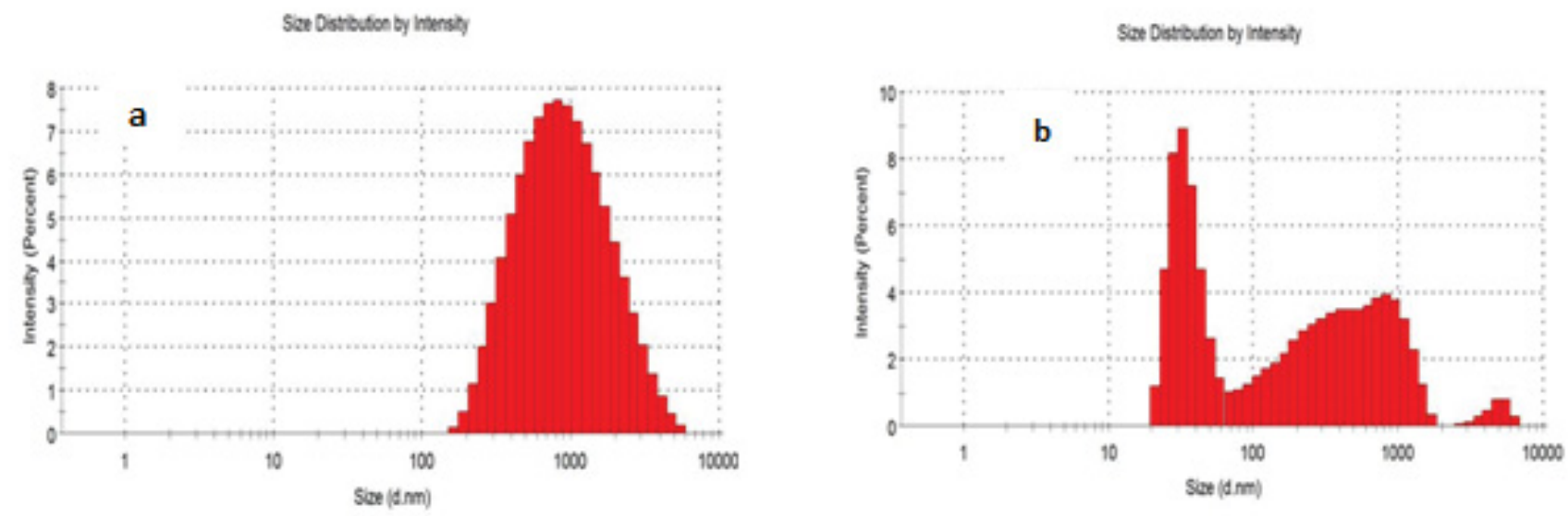

Figure 6: Particle size distribution histogram of (a) CHS; (b) COMP.

pore size of CHS increased from $12.67 \mathrm{~m}^{2} / \mathrm{g}$ to $33.46 \mathrm{~m}^{2} / \mathrm{g}$, $0.0266 \mathrm{~cm}^{3} / \mathrm{g}$ to $0.1347 \mathrm{~cm}^{3} / \mathrm{g}$ and $4.035 \mathrm{~nm}$ to $4.078 \mathrm{~nm}$ respectively after incorporation with silver to form the nanocomposite of CHS-silver. This may be attributed to reduction of agglomeration of $\mathrm{CHS}$ due to the presence of nanoparticles of silver in the polymer matrix of $\mathrm{CHS}$. The specific surface area of CHS in this work is higher than the $0.1698 \mathrm{~m}^{2} / \mathrm{g}$ and $5.5156 \mathrm{~m}^{2} / \mathrm{g}$ obtained by Thien, et al., [23] for bare CHS and fully deacetylated CHS respectively. In this vein, the pore volume of the prepared CHS increased after loaded with silver. This result is agreed with the results reported by Razzaz, et al., [24] on CHS nanofibers functionalized by $\mathrm{TiO}_{2}$ nanoparticles for the removal of heavy metal ions. According to International Union of Pure and Applied Chemistry (IUPAC) pores are classify base on diameter, for instance macropores ( $d>50$ $\mathrm{nm})$, mesopores $(2<\mathrm{d}<50 \mathrm{~nm})$ and micropores $(\mathrm{d}<2 \mathrm{~nm})$. Therefore, $\mathrm{CHS}$, and COMP are mesoporous in nature.

\section{Dynamic light scattering of CHS and COMP}

Intensity particle size distribution histogram of $\mathrm{CHS}$ and COMP in Figures $6 a$ and Figures $6 \mathrm{~b}$ indicate that $100 \%$ of particle sizes of CHS is within the range of $100-10000 \mathrm{~nm}$, with average particle size of $729 \mathrm{~nm}$, while that of COMP shows two major peaks: First peak which falls within $10-100 \mathrm{~nm}$ reveals the presence of nanosilver of mean size of $35.71 \mathrm{~nm}$; second peak within 100-1000 nm indicates CHS of reduced particle sizes of mean size of $360.4 \mathrm{~nm}$. The high average particles size of CHS obtained in this study may be attributed to the absence of electrostatic hindrance to the repulsion between protonated amino groups [25]. From Table 2, CHS mean particle size was $729 \mathrm{~nm}$ and latter reduced to 360.4 $\mathrm{nm}$ after incorporation of nanosilver. This may be attributed to increase in protonation of amino group, increasing the propensity of CHS cross-linking, resulting in a more compressed structure due to creation of electrostatic repulsion [26].
Table 2: DLS results of CHS and COMP.

\begin{tabular}{|l|l|l|}
\hline Parameter & CHS & COMP \\
\hline Average particle size $(\mathrm{nm})$ & 729 & 360.4 \\
\hline Polydispersity index & 0.275 & 0.388 \\
\hline
\end{tabular}

Also, Table 2 shows the polydispersity indices (PDI) for CHS and COMP to be 0.275 and 0.388 respectively, these are within the range of 0.1-0.4 indicating that particles of CHS and its nanocomposite are moderately polydisperse but having that of composite particles to be more polydispersive.

\section{High resolution scanning electron micrographs (HRSEM) of CHS and COMP}

Figure 7a and Figure 7b shows the HRSEM micrographs of $\mathrm{CHS}$ and COMP. The CHS micrograph shows needle-like crystalline structure with smooth surface as fine powder. While, after doped with silver nanoparticles due agglomeration of the nanosilver, the surface becomes rough and porous with crystals-like silver nanoparticles seen evenly distributed across the surface (Figure $7 \mathrm{~b}$ ), this trend is aligned with result from previous study [27]. The needle-like structure obtained for $\mathrm{CHS}$ is aligning with what Krishnaveni and Ragunathan [28] obtained as the morphology of CHS. Further proof to the combination of nanosilver and CHS was showed on electron dispersive spectra (EDS) presented in Figure 7b. Hydrogen being the only element in the periodic table with only K-shell is not detectable with EDS [29].

Figure $8 \mathrm{a}$ and Figure $8 \mathrm{~b}$ is the EDS and elemental composition histograms of $\mathrm{CHS}$ and $\mathrm{CHS}$-silver spectrum showing the key elements (carbon, nitrogen and oxygen) and (C, N, O and $\mathrm{Ag}$ ) on the surface chemical structure of the samples respectively. The presence of $\mathrm{Na}$ and Si signals may be attributed to strong bond formed by $\mathrm{Na}$ as micronutrient commonly found 

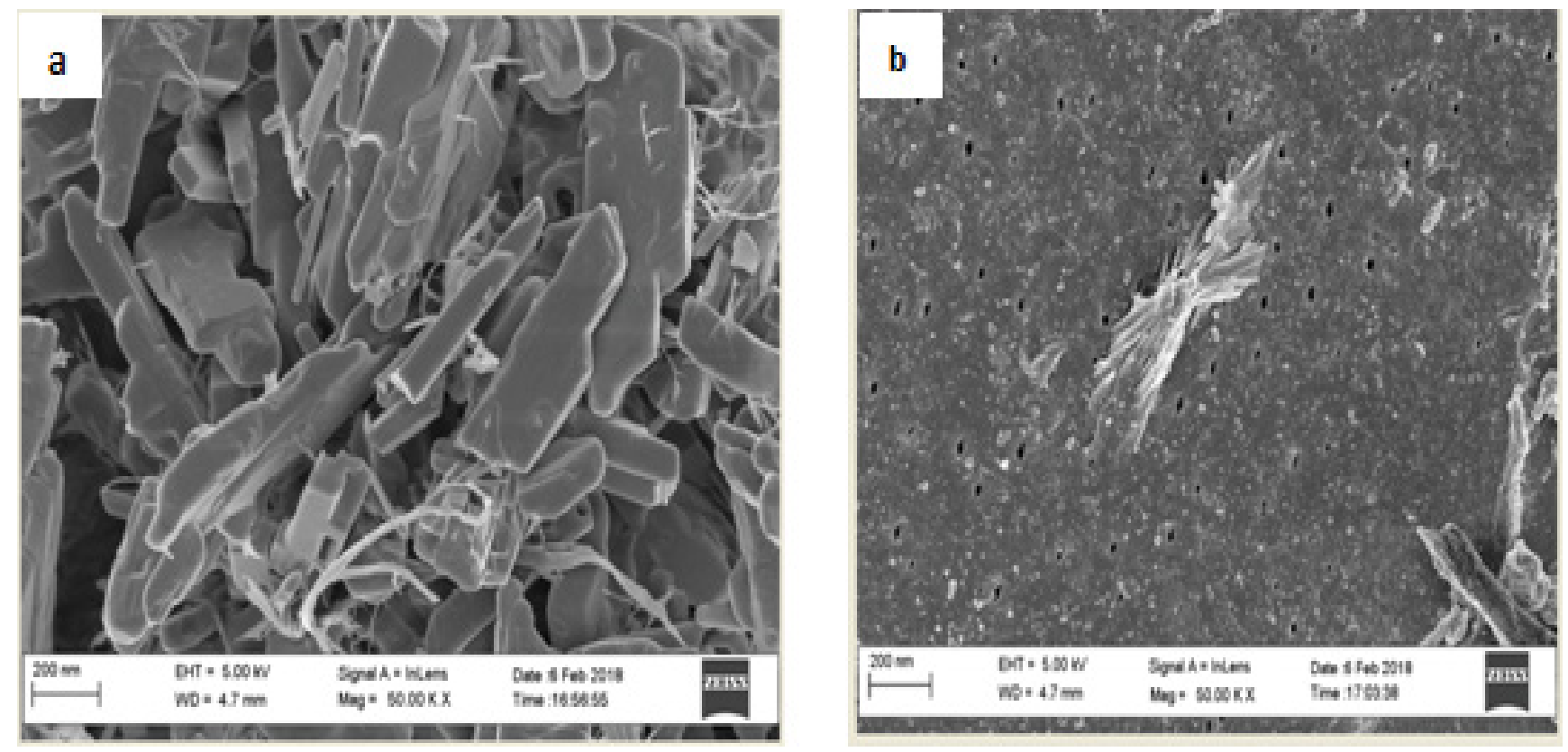

Figure 7: HRSEM micrograph of (a) CHS; (b) COMP.
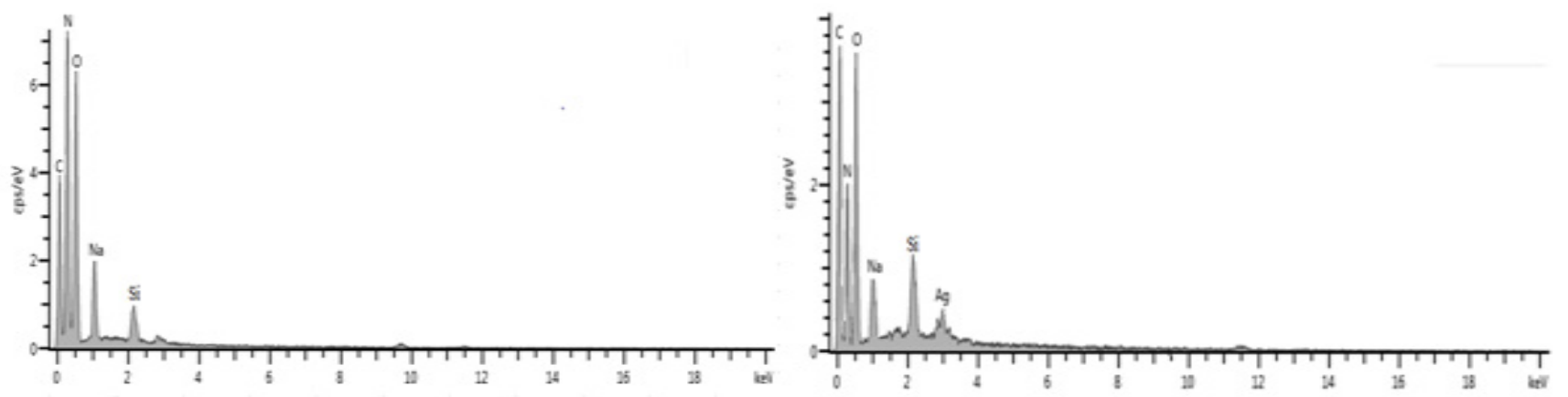

Figure 8: EDS Spectrum for (a) CHS; (b) COMP.

in both $\mathrm{CHS}$ and plant extracts and to interferences of debris of silicon-lithium detector as component of the machine used, due to prolonged usage respectively.

\section{Batch adsorption of heavy metals in electroplat- ing wastewater}

The CHS and COMP produced were employed to treat wastewater from electroplating plant. The influences of contact time, adsorbent dose and temperature on the adsorption of the selected metal ions by developed adsorbents were investigated and the results obtained are hereby presented as follows.

Influence of contact time on the removal of $\mathrm{Cu}$ and $\mathrm{Fe}$ ions: Figure 9 represents the influences of contact time on the percentage uptake of $\mathrm{Cu}$ and $\mathrm{Fe}$ ions by $\mathrm{CHS}$ and COMP (volume $=50 \mathrm{~cm}^{3}$, adsorbent dosage $=25 \mathrm{mg}$, temperature $=$ $30{ }^{\circ} \mathrm{C}$, stirring speed $=200 \mathrm{rpm}$ ).

The relationship between the percentage removals of metal ions with the contact time, as shown in Figure 9, shows that both adsorbents initial removal of $\mathrm{Cu}$ and Fe ions from wastewater very fast. The optimum contact time for the removal of Fe ions by CHS and COMP was 45 minutes while the optimum percentage removals of $\mathrm{Cu}$ ions on both adsorbents was attained in about 30 minutes. The initial fast rate of removal of both metal ions can be attributed to the initial large availability of a number of binding sites on the adsorbents, while later slow removal rate may be due to weak interaction between the adsorbates and the adsorbents as a result of a reduction in the number of binding sites [30]. It is thus obvious from Figure 9 that in a little time the proportion of both metal ions removed on the adsorbent was high. This can be due to the fact that more metal ions were available which encourage quick diffusion the ions from the wastewater to the free active sites on the adsorbents [31].

Influence of adsorbent dose on the removal of $\mathrm{Cu}$ and $\mathrm{Fe}$ ions: The amount of adsorbent played an important role in an adsorption process, as it describes the adsorbent's ability to remove metal ions in terms of the number of active binding sites.

As shown in Figure 10, the proportion of both ions re- 


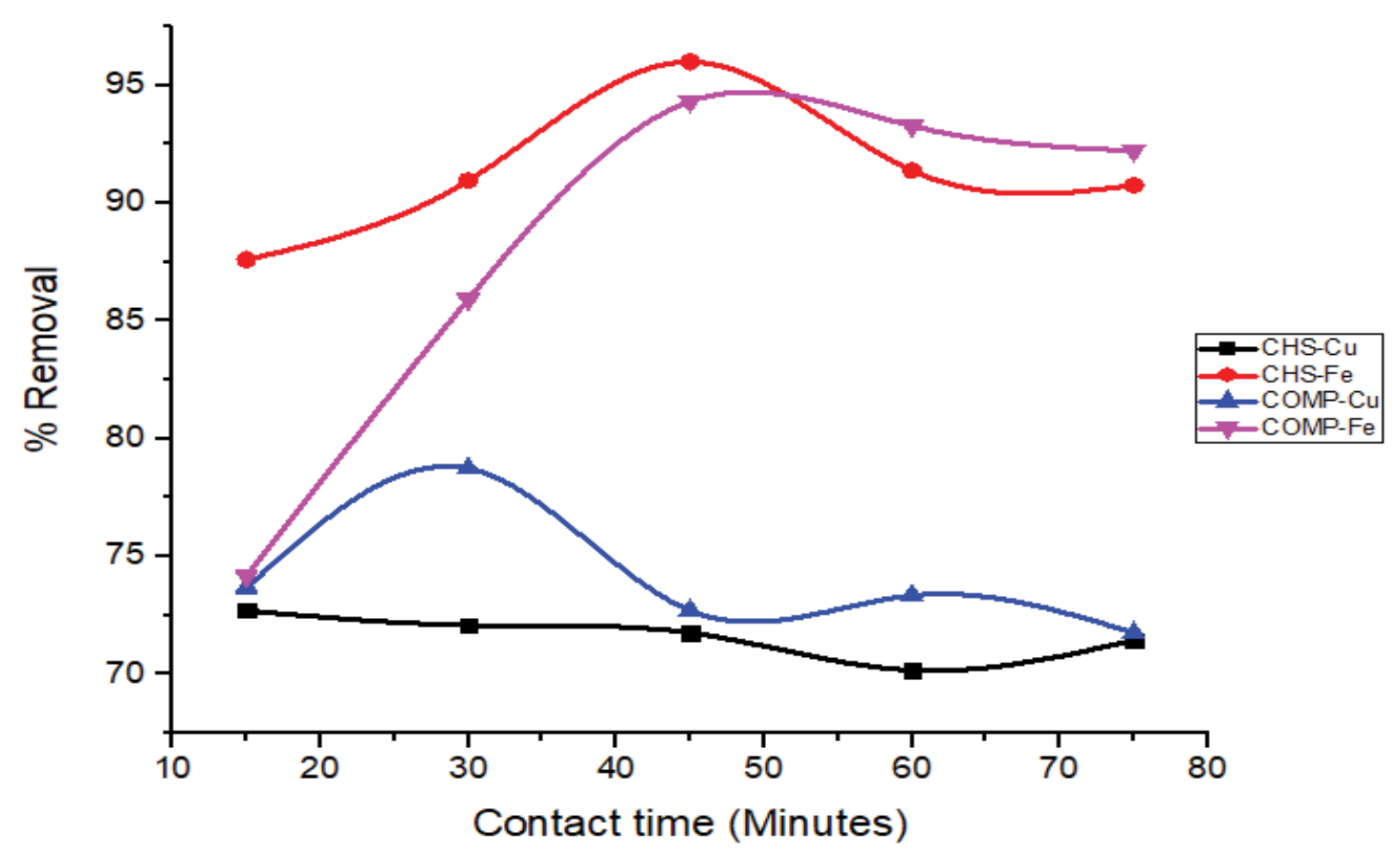

Figure 9: Effect of contact time on $\mathrm{Cu}$ and Fe removal.

Note: CHS: CHS and COMP: Chitosan-silver nanocomposite.

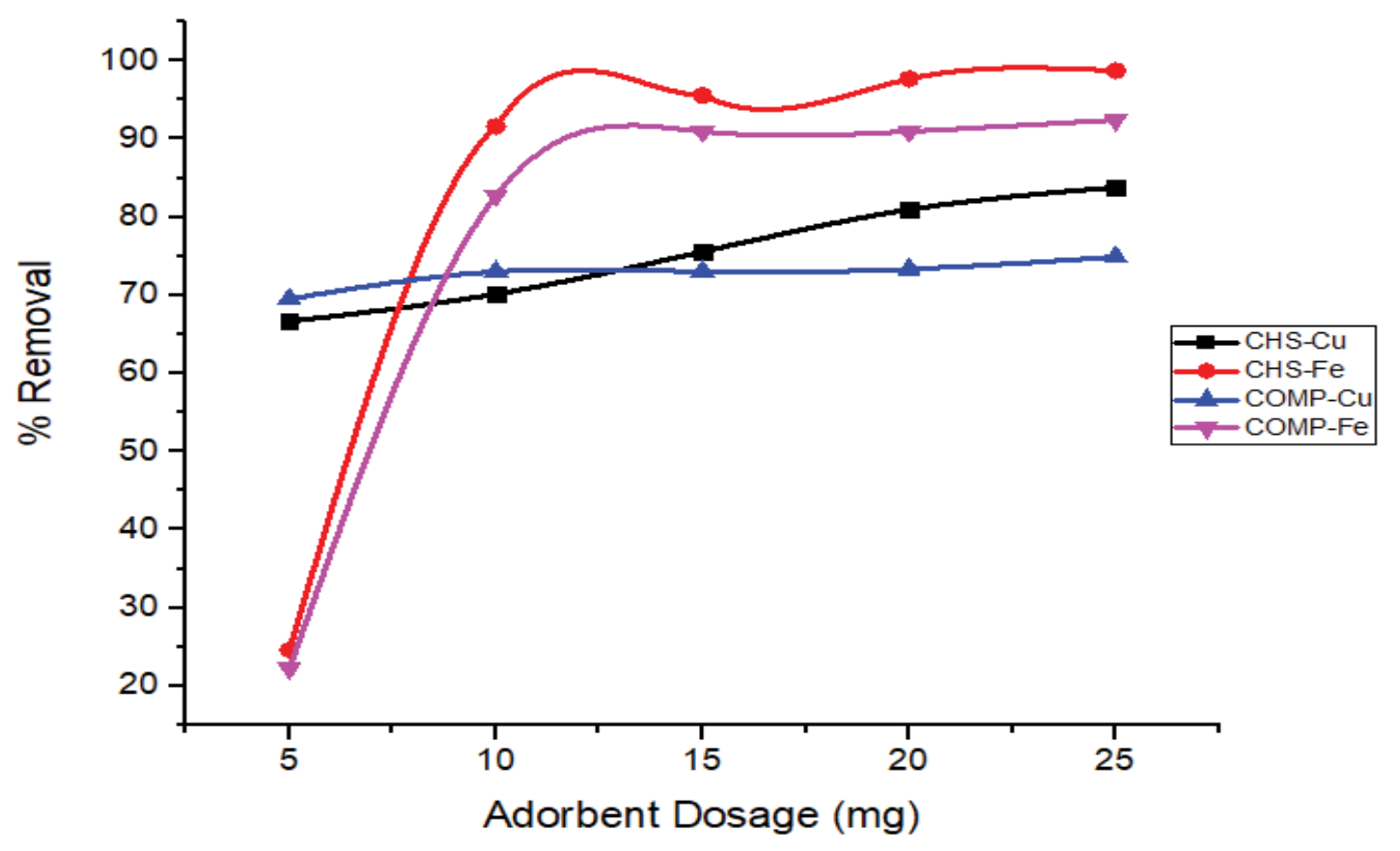

Figure 10: Effect of adsorbent dosage on $\mathrm{Cu}$ and Fe removal.

moved increases with the dose of adsorbents (5 to $25 \mathrm{mg}$ ). This high removal of the metal ions may be as a result of the presence of more binding sites as the dose of adsorbent increased [32]. The initial percentage removal of Fe ions on both adsorbents was lower compared to $\mathrm{Cu}$ ions due to latter smaller ionic radius but as dosage increased the affinity of both adsorbents for Fe ions rise so leads to higher adsorption [33]. This result is consistent with the result obtained by
Priyanka, et al. [34] on the adsorption of $\mathrm{Pb}$ (II), $\mathrm{Cu}$ (II), and $\mathrm{Zn}$ (II) ions on the leaves of Urtica dioica as an inexpensive adsorbent.

Influence of temperature on the removal of $\mathrm{Cu}$ and $\mathrm{Fe}$ ions: The influence of change in temperature on the uptake of $\mathrm{Cu}$ and $\mathrm{Fe}$ ions by CHS and COMP at constant adsorbent dose, contact time and stirring speed was studied (Figure 11). 


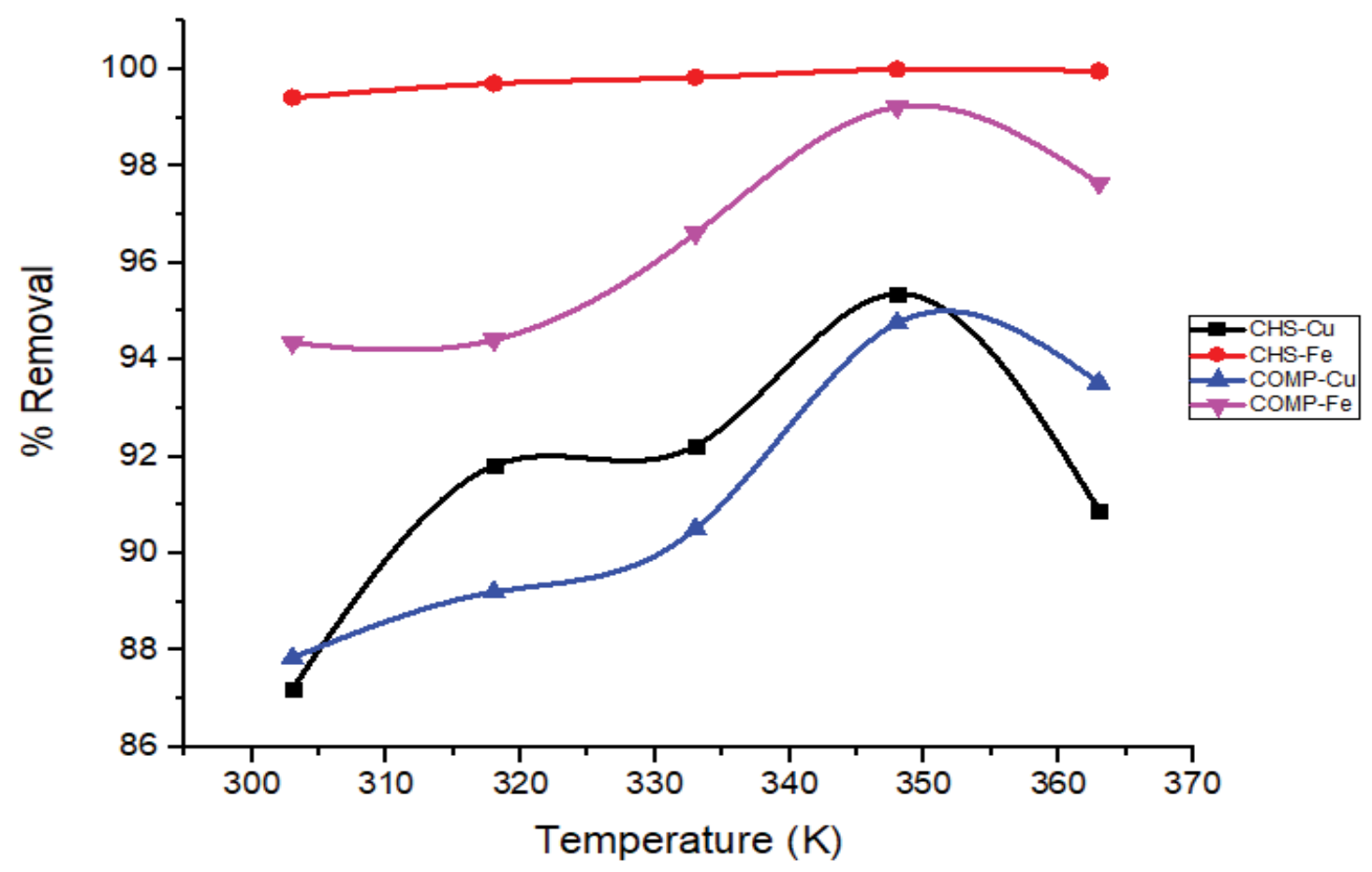

Figure 11: Effect of temperature on $\mathrm{Cu}$ and Fe removal.

Table 3: Details of variables plots for the isotherm models.

\begin{tabular}{|l|l|l|l|l|}
\hline Isotherm model & Dependent variable & Independent variable & Slope & Intercept \\
\hline Freundlich & $\operatorname{lnq}_{\mathrm{e}}$ & $\operatorname{lnC} \mathrm{C}_{\mathrm{e}}$ & $1 / \mathrm{n}$ & $\operatorname{InK}_{\mathrm{f}}$ \\
\hline Jovanovic & $\operatorname{lnq}_{\mathrm{e}}$ & $\mathrm{C}_{\mathrm{e}}$ & $-\mathrm{K}_{\mathrm{j}}$ & $\operatorname{Inq}_{\max }$ \\
\hline Harkin - Jura & $1 / \mathrm{q}_{\mathrm{e}}^{2}$ & $\log \mathrm{C}_{\mathrm{e}}$ & $-1 / \mathrm{A}_{\mathrm{HJ}}$ & $\mathrm{B}_{\mathrm{HJ}} / \mathrm{A}_{\mathrm{HJ}}$ \\
\hline Temkin & $\mathrm{q}_{\mathrm{e}}$ & $\ln \mathrm{C}_{\mathrm{e}}$ & $\mathrm{K}_{1}$ & $\mathrm{~K}_{1} \ln \mathrm{KK}_{2}$ \\
\hline
\end{tabular}

From Figure 11 it is observed that the percentage uptake of $\mathrm{Cu}$ and $\mathrm{Fe}$ ions by $\mathrm{CHS}$ and COMP increased respectively as temperature rise from 303 to $348 \mathrm{~K}$. These outcomes concurred with the findings of [35] on the removal of $\mathrm{Cu}^{2+}$ by activated carbon produced from grape bagasse. This study shows that the removal of Fe ions by CHS was significantly influenced by the change in temperature compared to COMP.

Generally, increased temperature is expected to significantly induce the adsorption of metal ions by adsorbents, easing more binding sites and movement of the adsorbates from the bulky aqueous medium to the adsorbent binding sites [36]. But in this study, the adsorption of $\mathrm{Cu}$ and Fe ions by $\mathrm{CHS}$ and COMP at a lower temperature of $303 \mathrm{~K}$ was initially fast and later became slowly as temperature increased. This is supported by the result reported by Md. Sayedur and Katherine [37] on metal ions removal from aqueous solutions by Kappaphycus sp.

Isotherm Models of $\mathrm{Cu}$ and Fe ions Adsorption: In this study, four isotherm models were adopted: Freundlich, Jovanovich, Harkin Jura and Temkin Isotherm. Using adsorption data obtained, the isotherms were plotted linearly and the constants, standard errors, and correlation coefficients $\left(R^{2}\right)$ of the model were calculated. The fitness of adsorption data into the selected isotherm models was checked using $\mathrm{R}^{2}$ and standard error values. The relationship presented in Equations 3, 4, 5 and 6 represent Freundlich, Harkins-Jura, Jovanovic and Temkin isotherm models respectively.

$$
\begin{aligned}
& \operatorname{Inq}_{\mathrm{e}}=\operatorname{InK}_{\mathrm{f}}+\frac{1}{\mathrm{n}} \operatorname{InC}_{\mathrm{e}} \\
& \frac{1}{\mathrm{q}_{\mathrm{e}}^{2}}=\frac{B_{H J}}{A_{H J}}-\frac{1}{A_{H J}} \operatorname{LogC}_{\mathrm{e}} \\
& \mathrm{Inq}_{\mathrm{e}}=\operatorname{Inq}_{\max }+\mathrm{K}_{\mathrm{j}} \operatorname{InC}_{\mathrm{e}} \\
& \mathrm{q}_{\mathrm{e}}=\mathrm{K}_{1} \operatorname{InK}_{2}+\mathrm{K}_{1} \operatorname{InC}_{\mathrm{e}}
\end{aligned}
$$

The Table 3 shows the dependent and independent variables plotted to obtained the respective slope and intercept for each isotherm model. The obtained slopes and intercepts were subsequently used to calculate the various isotherm parameters required to explain the adsorption of $\mathrm{Cu}$ and $\mathrm{Fe}$ ions.

Table 3 shows the Freundlich constants $\left(\mathrm{K}_{\mathrm{f}}\right)$ as the adsorption capacities of the prepared adsorbents for $\mathrm{Cu}$ and Fe ions. The higher adsorption capacities of both adsorbents for Fe ions compare to $\mathrm{Cu}$ ions can be explained by their higher af- 
Citation: Sumaila A, Ndamitso MM, lyaka YA, et al. (2020) The Role of Chitosan (CHS) and Chitosan-Silver Nanoadsorbents (COMP) in Adsorption of $\mathrm{Cu}$ (II) and Fe (II) lons from Electroplating Wastewater. Adv Environ Stud 4(2):318-330

Tables 4: Isotherm models parameters for the adsorption of $\mathrm{Cu}$ and Fe ions using CHS and COMP.

\begin{tabular}{|c|c|c|c|c|}
\hline & \multicolumn{2}{|l|}{ CHS } & \multicolumn{2}{|l|}{ COMP } \\
\hline \multirow{2}{*}{$\begin{array}{l}\text { Isotherm Models } \\
\text { Jovanovic }\end{array}$} & \multicolumn{2}{|l|}{ Metals } & \multicolumn{2}{|l|}{ Metals } \\
\hline & $\mathrm{Cu}$ & $\mathrm{Fe}$ & $\mathrm{Cu}$ & $\mathrm{Fe}$ \\
\hline$K_{j}$ & 0.348 & 0.211 & 0.348 & 0.218 \\
\hline $\mathrm{q}_{\max }$ & 7.907 & 11.900 & 7.905 & 11.905 \\
\hline $\mathrm{R}^{2}$ & 0.999 & 0.999 & 0.999 & 0.977 \\
\hline Standard error & $6.0 \times 10^{-4}$ & $2.34 \times 10^{-6}$ & $4.0 \times 10^{-4}$ & 0.068 \\
\hline \multicolumn{5}{|l|}{ Freundlich } \\
\hline$K_{f}$ & 6.402 & 11.759 & 6.377 & 10.907 \\
\hline$N$ & -11.620 & -515.464 & -11.232 & -39.154 \\
\hline $\mathrm{R}^{2}$ & 0.959 & 0.856 & 0.988 & 0.919 \\
\hline Standard error & $7.5 \times 10^{-3}$ & $1.1 \times 10^{-3}$ & $4.0 \times 10^{-3}$ & $7.17 \times 10^{-3}$ \\
\hline \multicolumn{5}{|l|}{ Temkin } \\
\hline $\mathrm{K}_{1}$ & -0.620 & -0.023 & -0.641 & -0.352 \\
\hline $\mathrm{K}_{2}$ & $3.5 \times 10^{-5}$ & $1.2 \times 10^{-22}$ & $5.16 \times 10^{-5}$ & $6.35 \times 10^{-28}$ \\
\hline $\mathrm{R}^{2}$ & 0.966 & 0.856 & 0.990 & 0.954 \\
\hline Standard error & 0.0494 & 0.0129 & 0.0264 & 0.0582 \\
\hline \multicolumn{5}{|l|}{ Harkins-Jura } \\
\hline$A_{H J}$ & -130.513 & $-1.6 \times 10^{4}$ & -126.326 & -1127.39 \\
\hline $\mathrm{B}_{\mathrm{HJ}}$ & -3.114 & -113.961 & -3.033 & -9.433 \\
\hline $\mathrm{R}^{2}$ & 0.946 & 0.855 & 0.984 & 0.911 \\
\hline Standard error & $3.4 \times 10^{-3}$ & $1.56 \times 10^{-5}$ & $2.0 \times 10^{-4}$ & $1.0 \times 10^{-4}$ \\
\hline
\end{tabular}

Table 5: Kinetic models for $\mathrm{Cu}$ and Fe ions removal from electroplating wastewater using CHS and COMP.

\begin{tabular}{|c|c|c|c|c|}
\hline \multirow{3}{*}{$\begin{array}{l}\text { Kinetic Models } \\
\text { Pseudo-first order }\end{array}$} & \multicolumn{2}{|l|}{ CHS } & \multicolumn{2}{|l|}{ COMP } \\
\hline & \multicolumn{2}{|l|}{ Metals } & \multicolumn{2}{|l|}{ Metals } \\
\hline & $\mathrm{Cu}$ & $\mathrm{Fe}$ & $\mathrm{Cu}$ & $\mathrm{Fe}$ \\
\hline $\mathrm{K}_{1}$ & $5.33 \times 10^{-4}$ & $1.27 \times 10^{-3}$ & $1.33 \times 10^{-3}$ & $3.76 \times 10^{-3}$ \\
\hline $\mathrm{R}^{2}$ & 0.918 & 0.843 & 0.758 & 0.789 \\
\hline Standard error & 0.004 & 0.003 & 0.021 & 0.053 \\
\hline \multicolumn{5}{|c|}{ Pseudo-second order } \\
\hline $\mathrm{K}_{2}$ & $2.40 \times 10^{-4}$ & $2.90 \times 10^{-4}$ & $5.60 \times 10^{-4}$ & $9.40 \times 10^{-4}$ \\
\hline $\mathrm{R}^{2}$ & 0.918 & 0.847 & 0.766 & 0.771 \\
\hline Standard error & 0.004 & 0.003 & 0.001 & 0.014 \\
\hline \multicolumn{5}{|l|}{ Elovich } \\
\hline$\Delta$ & 21.7200 & 5.0300 & 9.600 & 1.630 \\
\hline$\Theta$ & $2.27 \times 10^{18}$ & $1.63 \times 10^{7}$ & $1.41 \times 10^{7}$ & 14.700 \\
\hline $\mathrm{R}^{2}$ & 0.972 & 0.777 & 0.595 & 0.950 \\
\hline Standard error & 0.006 & 0.078 & 0.063 & 0.104 \\
\hline \multicolumn{5}{|c|}{ Intraparticle diffusion } \\
\hline $\mathrm{K}_{\text {int }}$ & 0.015 & 0.069 & 9.600 & 0.200 \\
\hline L & 2.156 & 3.903 & $1.41 \times 10^{7}$ & 2.892 \\
\hline $\mathrm{R}^{2}$ & 0.956 & 0.814 & 0.595 & 0.997 \\
\hline Standard error & 0.007 & 0.071 & 0.001 & 0.006 \\
\hline
\end{tabular}


Citation: Sumaila A, Ndamitso MM, lyaka YA, et al. (2020) The Role of Chitosan (CHS) and Chitosan-Silver Nanoadsorbents (COMP) in Adsorption of $\mathrm{Cu}$ (II) and Fe (II) lons from Electroplating Wastewater. Adv Environ Stud 4(2):318-330

finities for Fe ions in aqueous media [38]. Moreover, the high values of $\mathrm{K}_{\mathrm{f}}$ for both adsorbents in this study may be due to the large number of binding sites in the CHS and the large surface area of the COMP.

The constants correlation coefficients $\left(R^{2}\right)$ and standard errors of the four selected adsorption isotherms are shown in Table 3. It is evident that adsorptions mechanism of the $\mathrm{Cu}$ and $\mathrm{Fe}$ ions by $\mathrm{CHS}$ and $\mathrm{CHS}$-silver nanocomposite fitted well to the Jovanovic isotherm model than other isotherm models tested which is based on its very high correlation coefficients approximately 1 and very low standard errors close to 0 . Thus, equilibrium data for the $\mathrm{Cu}$ and Fe adsorption onto $\mathrm{CHS}$ and CHS-silver nanocomposite fitted well into the isotherm models in the following order: Jovanovic > Harkin-Jura > Freundlich > Temkin.

Kinetic model of $\mathrm{Cu}$ and Fe ions adsorption: In the adsorption studies, mechanism and rate of adsorption of $\mathrm{Cu}$ and Fe ions by CHS and COMP were analyzed by applying different kinetic models. These models include Elovich, pseudo-first order, pseudo-second order and intraparticle models. Table 4 shows the values of the rate constants and other parameters obtained from the slopes and intercepts of the plots. The equations for these kinetic models were shown as equations 7, 8, 9 and 10 .

Pseudo-first order equation

$\operatorname{In}[\mathrm{C}]=\operatorname{In}\left[\mathrm{C}_{0}\right]-\mathrm{kt}$

Pseudo - second order kinetic model

$$
\frac{1}{[\mathrm{C}]}=\frac{1}{\left[\mathrm{C}_{0}\right]}=\mathrm{kt}
$$

Elovich kinetic model

$$
\mathrm{C}=\frac{1}{\delta} \operatorname{In}(\theta \delta)+\frac{1}{\delta} \operatorname{In}(\mathrm{t})
$$

Intraparticle kinetic model

$$
\mathrm{q}_{\mathrm{t}}=\mathrm{K}_{\mathrm{i}} \mathrm{t}^{1 / 2}+\mathrm{C}
$$

From Table 5, it can be seen that the standard errors of Pseudo-second order model for the removal of the selected metal ions on both adsorbents were lower compare to other kinetic models tested. This suggests that Pseudo-second order kinetic model better described adsorption kinetics of $\mathrm{Cu}$ and Fe onto CHS. The Pseudo-second order rate constants $\mathrm{K}_{2}$ (Table 5) for the adsorption of Fe were found to be higher compare to that of $\mathrm{Cu}$, which supports that the uptake of Fe ions by both adsorbents was more favourable. This outcome agreed with results reported by Arshadi, et al. [39] and Meitei and Prasad [40]. In addition, Table 5 shows that the values of Elovich constants are high; this implies increase in adsorption rate. Also, to explain the absence of metal ions removal on heterogeneous surfaces, the kinetic data did not fit onto Elovich kinetic model [41].

Thermodynamic studies of the $\mathrm{Cu}$ and $\mathrm{Fe}$ ions removal: The nature of an adsorption process can be derived from thermodynamic studies. The set parameters are the Gibbs energy $\left(\Delta \mathrm{G}^{\circ}\right)$, changes in enthalpy $\left(\Delta \mathrm{H}^{\circ}\right)$ and changes in entropy $\left(\Delta S^{\circ}\right) . \Delta G^{\circ}$ indicates the spontaneity of the adsorption. So, negative value of $\Delta \mathrm{G}^{\circ}$ at a certain temperature indicates spontaneous adsorption. The $\Delta \mathrm{G}^{\circ}$ of adsorption process is usually determined by Van't Hoff equation (Equation 11) [42]:

$$
\Delta G^{\circ}=-R T I n K
$$

Equation 12 shows the relationship between $\Delta \mathrm{H}^{\circ}, \Delta \mathrm{S}^{\circ}$ and $\Delta \mathrm{G}^{\circ}$, while after substitution of Equation 11 into Equation 12, the relationship between equilibrium constant and temperature is presented as Equation 13.

$$
\Delta G^{\circ}=-R T I n K=\Delta H^{\circ}-T \Delta S^{\circ}
$$

Table 6: Gibbs free energy $(\mathrm{KJ} / \mathrm{mol})$, Enthalpy change $(\mathrm{KJ} / \mathrm{mol})$ and Entropy Change $(\mathrm{KJ} / \mathrm{molK})$ for the removal of $\mathrm{Cu}$ and $\mathrm{Fe}$ ions on $\mathrm{CHS}$ and COMP.

\begin{tabular}{|l|l|l|l|}
\hline & & Heavy metal ions & Fe \\
\hline Adsorbent & Temperature (K) & Cu & -1.731 \\
\hline CHS & 303 & -1.401 & -1.825 \\
\hline & 318 & -1.607 & -1.914 \\
\hline & 333 & -1.695 & -2.005 \\
\hline COMP & 348 & -1.868 & -2.091 \\
\hline & 363 & -1.804 & -1.619 \\
\hline & 303 & -1.484 & -1.718 \\
\hline & 318 & -1.576 & -1.830 \\
\hline CHS & 333 & -1.787 & -1.991 \\
\hline & 348 & -1.898 & -2.057 \\
\hline COMP & 363 & -1.932 & 0.111 \\
\hline & $\Delta \mathrm{H}$ & 0.781 & 0.006 \\
\hline & $\Delta \mathrm{S}$ & 0.007 & 853.350 \\
\hline & $\Delta \mathrm{H}$ & 1006.376 & 8.120 \\
\hline
\end{tabular}


Citation: Sumaila A, Ndamitso MM, lyaka YA, et al. (2020) The Role of Chitosan (CHS) and Chitosan-Silver Nanoadsorbents (COMP) in Adsorption of $\mathrm{Cu}$ (II) and Fe (II) lons from Electroplating Wastewater. Adv Environ Stud 4(2):318-330

$$
\text { Ink }=\frac{-\Delta \mathrm{H}^{\mathrm{o}}}{\mathrm{RT}}+\frac{\Delta \mathrm{S}^{\mathrm{o}}}{\mathrm{R}}
$$

Where $\mathrm{K}$ and $\mathrm{R}$ represent equilibrium and gas constants respectively

The slope and intercept of the plot of InK against $1 / \mathrm{T}$ as a straight line were used to calculate the values of $\Delta \mathrm{H}^{\circ}$ and $\Delta \mathrm{S}^{\circ}$ respectively. The Table 6 shows that positive $\Delta H^{\circ}$ values for the adsorption of $\mathrm{Cu}$ and Fe ions by both $\mathrm{CHS}$ and COMP were obtained. This indicates that the adsorption of these metals is endothermic [43]. The $\Delta S^{\circ}$ describes the degree of randomness during adsorption process. The positive values of $\Delta S^{\circ}$ in Table 6 show that randomness at the adsorbent-solution interface increase and also, the affinity of the adsorbents for the metal ions was enhanced $[44,45]$.

Table 6 shows the negative $\Delta G^{\circ}$ values for the removal of $\mathrm{Cu}$ and $\mathrm{Fe}$ ions in $\mathrm{CHS}$ and COMP which indicate that the adsorption processes were feasible and spontaneous. It was also noticed that as temperature increases, the $\Delta \mathrm{G}^{\circ}$ values decrease indicating favourable adsorption at elevated temperatures [46].

\section{Conclusion}

Preparation of nanocomposite of CHS and silver nanoparticles was successful. Both the CHS and its nanocomposite proved to be effective adsorbents for the removal of $\mathrm{Cu}$ (II) and Fe (II) ions from electroplating wastewater. The presence of functional groups revealed by FTIR spectrum as active sites in this adsorbent helped to bind $\mathrm{Cu}$ (II) and Fe (II) ions on the adsorbent surface. The adsorptions of the selected metal ions depend on contact time, adsorbent dose and temperature. Also, the results shown Jovanovic isotherm model best fitted the removal of $\mathrm{Cu}$ and $\mathrm{Fe}$ ions. The Pseudo-second kinetic model was a better model for their adsorption. Therefore, it is believed that this nanocomposite as an adsorbent can serve as an inexpensive alternative to remove heavy metals from electroplating wastewater.

\section{Acknowledgments}

Financial support received from Tertiary Education Trust Fund (TETFUND) Nigeria with grant number TETFUND/FUTMINNA/2016-2017/6 $\mathrm{BRP} / 05$ is very much appreciated.

\section{References}

1. Tchounwou PB, Yedjou CG, Patlolla AK, et al. (2012) Heavy metal toxicity and the environment. EXS 101: 133-164.

2. Ezzat AK, Algharib AM (2013) Removal of strontium from industrial wastewater using capsules and leaves of castor been and jojoba plants. Zagazig Journal of Agricultural Research 40: 10-22.

3. Yao-Jen T, Chen-Feng Y, Zhonghao Z, et al. (2014) Strontium removal in seawater by means of composite magnetic nanoparticles derived from industrial sludge. Water 8: 357.

4. Sivasangari S, Suseendhar S, Suresh K, et al. (2016) Characteristic study of electroplating and dye industrial effluents. International Journal of Innovative Research in Science, Engineering and Technology 5: 2319-8753.

5. Barakat MA (2011) New trends in removing heavy metals from industrial wastewater. Arabian Journal of Chemistry 4: 361-377.

6. Khulbe KC, Matsuura T (2018) Removal of heavy metals and pollutants by membrane adsorption techniques. Applied Water Science 8: 19.

7. Akolo SA, Kovo AS (2015) Comparative study of adsorption of copper ion onto locally developed and commercial chitosan. Journal of Encapsulation and Adsorption Sciences 5: 21-37.

8. Opeolu BO, Bamgbose O, Arowolo T, et al. (2010) Utilization of biomaterials as adsorbents for heavy metals' removal from aqueous matrices. Scientific Research and Essays 5: 1780-1787.

9. GangSeob J, Zhao Q, Markus JB (2015) Mechanical properties and failure of biopolymers: Atomistic reactions to macroscale response. Top Curr Chem 369: 317-343.

10. Maduka HCC, Ugwu CE, Okpogba AN, et al. (2015) The efficacy of chitosan obtained from Nigerian snail shell for the treatment of waste water effluent. Journal of Biodiversity and Environmental Sciences 7: 9-15.

11. Zhitong Y, Meisheng X, Haiyan L, et al. (2014) Bivalve shell: Not an abundant useless waste but a functional and versatile biomaterial. Critical Reviews in Environmental Science and Technology 44: 2502-2530.

12. Sobhanardakani S, Zandipak R, Parvizimosaed H, et al. (2014) Efficiency of chitosan for the removal of $\mathrm{Pb}$ (II), Fe (II) and $\mathrm{Cu}$ (II) ions from aqueous solutions. Iranian Journal of Toxicology 8: 1145-1151.

13. Sotiriou GA, Sannomiya T, Teleki A, et al. (2010) Non-toxic dry-coated nanosilver for plasmonic biosensors. Advanced Functional Material 21: 4250-4257.

14. Hajji S, Younes I, Ghorbel-Bellaaj O, et al. (2014) Structural differences between chitin and chitosan extracted from three different marine sources. International Journal Biology and Macromolecules 65: 298-306.

15. Wang Y, Pitto-Barry A, Habtemariam A, et al. (2016) Nanoparticles of chitosan conjugated to organo-ruthenium complexes. Inorganic Chemistry Frontier 3: 1058-1064.

16. Ahmad MB, Lim JJ, Shameli K, et al. (2011) Synthesis of silver nanoparticles in chitosan, gelatin and chitosan/gelatin bionanocomposites by a chemical reducing agent and their characterization. Molecules 16: 7237-7248.

17. Shameli K, Ahmad M B, Zargar M (2011) Synthesis and characterization of silver/montmorillonite/chitosan bionanocomposites by chemical reduction method and their antibacterial activity. Int J Nanomedicine 6: 271-284.

18. Astalakshmi A, Nima P, Ganesan V (2013) A green approach in the synthesis of silver nanoparticles using bark of Eucalyptus globulus, Labill. International Journal of Pharmaceutical Sciences Review and Research 23: 47-52.

19. Gunatilake SK (2015) Methods of removing heavy metals from industrial wastewater. Journal of Multidisciplinary Engineering Science Studies 1: 1-7.

20. Bao Q, Dun Z, Peng Q (2011) Synthesis and characterization of silver nanoparticle and graphene oxide nanosheet composites as a bactericidal agent for water disinfection. Journal of Colloid and Interface Science 360: 463-470.

21. Mie R, Samsudin MW, Din LB, et al. (2014) Synthesis of silver nanoparticles with antibacterial activity using the lichen Parmotrema praesorediosum. International Journal of Nanomedicine 9: 121-127. 
Citation: Sumaila A, Ndamitso MM, lyaka YA, et al. (2020) The Role of Chitosan (CHS) and Chitosan-Silver Nanoadsorbents (COMP) in Adsorption of $\mathrm{Cu}$ (II) and Fe (II) lons from Electroplating Wastewater. Adv Environ Stud 4(2):318-330

22. Jain S, Mehata MS (2017) Medicinal plant leaf extract and pure flavonoid mediated green synthesis of silver nanoparticles and their enhanced antibacterial property. Scientific Reports 7: 15867.

23. Thien DT, An NT, Hoa NT (2015) Preparation of fully deacetylated chitosan for adsorption of $\mathrm{Hg}(\mathrm{II})$ ion from aqueous solution. Chemical Science Journal 6.

24. Razzaz A, Ghorban S, Hosayni L, et al. (2016) Chitosan nanofibers functionalized by $\mathrm{TiO} 2$ nanoparticles for the removal of heavy metal ions. Journal of the Taiwan Institute of Chemical Engineers 58: 333-343.

25. Maciel V, Yoshida C, Pereira S, et al. (2017) Electrostatic self-assembled chitosan-pectin nano-and microparticles for insulin delivery. Molecules 22: 1707.

26. Pervez MN, Stylios GK (2018) Investigating the synthesis and characterization of a novel "Green" H2O2-assisted, water-soluble chitosan/polyvinyl alcohol nanofiber for environmental end uses. Nanomaterials (Basel) 8: 395.

27. Zhang X, Liu Z, Shen W, et al. (2016) Silver nanoparticles: Synthesis, characterization, properties, applications, and therapeutic approaches. International Journal of Molecular Sciences 17 1534.

28. Krishnaveni B, Ragunathan R (2015) Extraction \& characterization of chitin and chitosan from Bionetria CBNR BKRR, synthesis of their bionanocomposites and study of their application. Indo Global Journal of Pharmaceutical Sciences 5: 40-52.

29. Khalid MH, Pervez MF, Uddin MJ, et al. (2018) Influence of natural dye adsorption on the structural, morphological and optical properties of TiO2 based photoanode of dye-sensitized solar cell. Materials Science-Poland 36: 93-101.

30. Das B, Mondal NK, Bhaumik R, et al. (2014) Insight into adsorption equilibrium, kinetics and thermodynamics of lead onto alluvial soil. International Journal Environmental Science Technology 11: 1101-1114.

31. Kaveeshwar A, Sanders M, Ponnusamy SK, et al. (2017) Chitosan as a biosorbent for adsorption of iron (II) from fracking wastewater. Polymers for Advanced Technologies 29: 961-969.

32. Gupta VK, Agarwal S, Saleh TA (2011) Synthesis and characterization of alumina-coated carbon nanotubes and their application for lead removal. Journal of Hazardous Material 185: 17-23.

33. Bankole MT, Abdulkareem AS, Mohammed IA, et al. (2019) Selected heavy metals removal from electroplating wastewater by purified and polyhydroxylbutyrate functionalized carbon nanotubes Adsorbent. Scientific Reports 9: 4475.

34. Priyanka T, Mahesh CV, Sushil KJ, et al. (2017) Adsorption of Pb
(II), Cu (II), and Zn (II) ions onto urtica dioica leaves (UDL) as a low cost adsorbent: Equilibrium and thermodynamic studies. Modern Chemistry 5: 11-18.

35. Hakan D, Cihan G (2016) Adsorption of copper (II) from aqueous solutions on activated carbon prepared from grape bagass. Journal of Cleaner Production 124: 103-113.

36. Areco MM, Afonso MS (2010) Copper, zinc, cadmium and lead biosorption by Gymnogongrus torulosus. Thermodynamics and kinetics studies. Biointerfaces 81: 620-628.

37. Md Sayedur R, Kathiresan VS (2015) Heavy metal adsorption onto Kappaphycus sp. from aqueous solutions: The use of error functions for validation of isotherm and kinetics models. BioMed Research International 2015.

38. Arivoli S, Marimuthu V, Mohamed ARJ (2013) Kinetics of batch adsorption of iron (II) ions from aqueous solution using activated carbon from Strychnos Nux-Vomica L. International Journal of Scientific and Engineering Research 4: 407-417.

39. Arshadi M, Amiri MJ, Mousavi S (2014) Kinetic, equilibrium and thermodynamic investigations of $\mathrm{Ni}$ (II), Cd (II), Cu (II) and Co (II) adsorption on barley straw ash. Water Resources and Industry 6: 1-17.

40. Meitei MD, Prasad MNV (2014) Adsorption of Cu (II), Mn (II) and Zn (II) by Spirodela polyrhiza (L.) schleiden: Equilibrium, kinetic and thermodynamic studies. Ecological Engineering 71: 308-317.

41. Enos WW, Stephen A, Paul MS, et al. (2018) Removal of heavy-metals from wastewater using a hydrous alumino-silicate mineral from Kenya. Bulletin of Chemical Society of Ethiopia 32: 39-51.

42. Rathod M, Mody K, Basha S (2014) Efficient removal of phosphate from aqueous solutions by red seaweed, Kappaphycus alverezii. Journal of Cleaner Production 84: 484-493.

43. Murthy CR, Ramesh P, Ramesh A (2011) Study of biosorption of $\mathrm{Cu}$ (II) from aqueous solutions by coconut shell powder. Chemical Science Journal 17: 1-15.

44. Maksin DD, Kljajević SO, Dolić MB (2012) Kinetic modelling of heavy metal sorption by vinyl pyridine based copolymer. Hem Ind 66: 795-804.

45. Somasundaram S, Sekar K, Gupta VK, et al. (2013) Synthesis and characterization of mesoporous activated carbon from rice husk for adsorption of glycine from alcohol-aqueous mixture. Journal of Molecular Liquids 177: 416-425.

46. Hamideh R, Ali AG, Habibollah Y, et al. (2012) Adsorption of Fe (II) ions from aqueous phase by chitosan adsorbent: Equilibrium, kinetic, and thermodynamic studies. Desalination and Water Treatment 50: 348-359.

DOI: $10.36959 / 742 / 228$

Copyright: (C) 2020 Sumaila A, et al. This is an open-access article distributed under the terms of the Creative Commons Attribution License, which permits unrestricted use, distribution, and reproduction in any medium, provided the original author and source are credited. 